\title{
THE INSTRUCTION OF NEW EMPLOYES IN METHODS OF SERVICE
}

\author{
By Arthur Williams,
}

The New York Edison Company.

One of the problems-perhaps the greatest-before the business world of the United States at the time this article is written is how will the industries of the United States be affected when the war in Europe is brought to a close? That business in this country will be affected is a belief too universal to require discussion. Whether a trade war will follow the military war and the nature of such a contest and its permanent effects, as well as temporary changes, is the problem for which so many are earnestly seeking a solution. If there is to be a trade war, permanent in character, in what respect are the industries of the United States prepared? Plant and equipment of United States industries are probably equal to plant and equipment of any other nation. For example, our railroads have increased the weight of their rails, the size of their locomotives, the capacity of their cars and the weight of their train loads to a point where further development will be difficult if, indeed, much further development is possible.

Plant and equipment in our factories have likewise kept pace with the development of our railroads. The electrical industry of this country is superior, both in its manufacturing and operating branches, to the electrical industries of any other nation. With the use of manufactured power, especially electric energy, production has ceased to be the predominant factor in industry. Prior to the outbreak of the European war, in almost every line of industry, the ability to produce was greater than the demands of the available markets; nor was the problem of transportation at all perplexing. In fact, there was much idle equipment. The predominant problem of industry for the past thirty years has been to stimulate consumption and thus increase demand.

An analysis of plant and equipment of American industries in comparison with similar industries in other countries indicates the United States should be able to hold her present trade, other than 
the present unusual demands, as the result of the war. But an analysis of the personnel of industry-if this term may be used to identify the workers-does not show so favorably in comparison.

Germany has long trained her workers and other of the leading nations have established facilities for training the so-called masses to a much greater extent than has been done in the United States. While it is true, then, that the industries of the United States have set the pace in the development of plant and equipment, it is not true that they have kept abreast of other leading nations in training the workers.

Our commercial world is now, however, fast realizing that the vast body of men which makes up our great armies of industry and commerce possesses a store of potentialities which as yet has received hardly more than an awakening touch. With this realization has come another-that to stimulate these powers the employer must provide some form of definite training to fit his employes for the requirements of his particular business. This statement should not be interpreted as a reflection upon the educational standards of our various school systems. If it must be construed as a criticism, it may be directed at the economic system which enables so many of our boys and young men, girls and young women, to enter business with their educations only half completed, or perhaps hardly begun.

It is not my purpose to quote figures, showing how many boys and girls leave school before finishing the elementary courses, nor to point out the small percentage of those who finish the high school courses, nor even to refer, other than in passing, to the small part of the whole--less than 5 per cent-who enter business with the advantage of a college or any other considerable degree of secondary education. These things are self-evident to one who contemplates the vast armies of unskilled and untrained men and women-for today women must be included in any consideration affecting the welfare of our industrial workers.

The problem of the half trained boy in business is not greater than that of the middle aged man. The boy in the first years of his business life can shift from job to job and each time he makes the shift secure perhaps a slightly increased wage. The grown man, however, must stick to his position because he is capable of filling no other, and oftentimes he is employed largely through the 
sentimentality of his employer. If by some misfortune he finds himself among the job hunters, his chances of doing as well for himself in another place are decidedly lessened. All of this is due primarily to the fact that either during his years of preparation for business or after he has entered the business field, the opportunities of finding and developing his best characteristics have been neglected.

While much attention is now being given to the subjects of employment, very little is actually known as to what methods may be devised by which can be determined the work for which a certain type of individual is best fitted. There are those who contend that this information can be ascertained by psychological analysis of individual characteristics, and, as a result, the best work for that person will be readily discovered. The second theory, and one which seems better suited for practical application, holds that the only way to determine the line of endeavor in which an individual will be most successful is by actual experience and accomplishment. It is because of these things partly that the employers of today are alive to the need of some constructive method of fitting employes for and advancing them in service. Corporations everywhere are either active in some form of educational work on behalf of their employes, or at least are considering the best methods for selecting employes and of applying training to insure best results in their business.

This new activity, which is really the fifth great subdivision of any large industrial enterprise, might aptly be termed "employe relations." It takes its place and is coming to be recognized as having equal importance with the other larger elements in the management of any considerable employing body. By way of amplifying this statement, it might be pointed out that when the first industrial corporation was organized, it consisted of three general subdivisions-production, financing and accounting, and marketing. It was soon recognized, however, that an important element was lacking, and the element of traffic or the transportation of products of industry was necessarily added as an executive or administrative requirement. With provision for these four subdivisions, executives of our industrial organizations, until very recent periods, have believed they were fulfilling all of the demands to be properly made upon them. 
More recently, however, attention has been given to the personnel or the human elements of the organization, with the result that there have come into existence, with varying degrees of effectiveness, activities which have entirely to do with employe relations specifically to the employing organization and in general to industry as a whole. Under the broad scope of "employe relations" the work is carried on of careful selection of employes and of fitting them for the specific and the best service of the employer. Under this heading also may be grouped the employer's efforts toward education, general as well as specific, the establishment of social organizations, sick and death benefits, of pensions or service annuities, of profitsharing or partnership, home acquiring and savings and loan activities.

By way of a change from a presentation of generalities to the consideration of a specific instance of corporation activity along educational lines, may be mentioned the educational work of The New York Edison Company. This now covers three organized fields-technical and practical engineering, accounting and the commercial service. While the actual training of the individual is of the first importance, it is nevertheless essential that the personality and the attitude of the student employe, as well as the graduate, shall be closely observed. A part of the value to be derived from training a man lies in the opportunity which this period of training gives the employer to study and analyze his characteristics, to become familiar with his personality and to find out about him those things which will best fit him for the service of his employerwhich perhaps, and probably, shall fit him best also to fulfill the obligations and opportunities of his own life.

To meet these conditions the company in question has established in connection with its educational work a record system, for the purpose of determining the relative efficiency of the employes in the accomplishment of its work-the rendering of a satisfactory public service. These records are kept by card indices through which the past and present services of the employe can be quickly determined and based upon these performances his chances of the future and of fulfilling higher positions may be determined with a fair degree of accuracy. The tendency is growing to promote or demote or occasionally request the resignation of employes as a result of the studies of these indices. With the establishment of 
the company's commercial schools in 1911, part of the primary work of that year consisted of a survey of the men and, in this connection, the necessary facts about their earlier education and employment, as well as the results secured in their present employment were obtained and recorded.

In the commercial department of the company there are more than five hundred employes, ranging from the office boys to the heads of departments, and everyone below the position of manager falls within the scope of the company's educational and record system. The plan becomes effective the moment anyone enters thc company's service, and, as indicated, it includes every representative of the company, large or small, who comes in contact with the public, either directly or by telephone or correspondence. This personal record continues as long as the employe remains in the service of the company. Blanks are provided for each item of information, the earliest entries including the name, address, age, the bureau entered and the immediate position. Then is recorded the education of the employe, whatever it has been, grammar school, high school or college, followed by the list of positions previously held. A new employe is assigned to minor duties, so that he may become acquainted with the organization and aims of the company, its recognition of responsibility to the public as a feature of service, in fact, all the more important duties of the position which the employe occupies. His capabilities and attitude toward his work are under constant observation and at suitable intervals are made matter of record. This is as important to the employe as to the company, as, at least eventually, all of these records form a basis for increases in salary and promotion to higher positions. They often form also a basis of recommendation to other employers who might have perhaps more immediately opportunities for the higher positions.

In passing it might be said that an employe, who has rendered good service, going out to take a higher position elsewhere, always goes with the fullest good will of the company. Perhaps the greatest encouragement to faithful service is the realization that it will be recognized outside as well as within the company and this also greatly encourages those who remain to better individual development and a higher degree of general service. The employes of the company are entitled to first consideration when promotions are in 
order. Their records are carefully studied and promotions are made wherever practicable from the ranks of the company. In the absence of special circumstances, new men take the lower positions.

The general method of "hiring and firing" is not followed. If a man is employed for some specific position in which he does not make good, effort is made to find another position in which his term of past service can be used cumulatively to the advantage both of the employe and of the company. The man who perhaps cannot get along with one manager may work cheerfully with another, or who cannot perform one kind of service may perform excellently another kind of service.

When the personal records, especially the earlier records, show an unfavorable report, transfers to different positions and departments are made, often with excellent results. Frequently, an earlier report of unsatisfactory service will be corrected by later reports. Frequently, also, inefficiency on the part of employes is not radical or permanent, but may be a matter of adjustment, either through a better understanding of the service required or a change in environment in which the employe has greater personal aptitude to render satisfactory service.

These human records are constantly becoming more accurate. As time passes they are based less and less upon the opinions of one person or even two or three persons, but become the result of a variety of surveys and studies in which the composite result will average a high degree of accuracy. One important point is that the record shall be made at the time-not left to memory or hazy impression. After a fair period of time the record should be a complete picture by which the employe can be identified by anyone fairly acquainted with him.

It should not be inferred that this "human survey" is the complete record by which an employe is judged. The employe's school work, covering a two years' course, is a part. Then there is the record for attendance, for coöperative or "team," as well as initiatory, effort, and even further effort is made to select men that are of the executive or administrative type. The commercial schools are conducted within the company's time and, it would seem needless to say, at the expense of the company. Enrollment and attendance are compulsory. Classes meet weekly and every alternate week there are written examinations based upon questions distrib- 
uted before the lectures. At the end of the year the student must have a rating of 75 per cent to pass, or falling below that point he must re-enroll and begin all over again. If he gets what is called the " $\mathrm{C}$ " rating, which is between 75 and 82 per cent, a special course of instruction is taken through the summer, with a later examination in the autumn, when it is expected that the student will have gained at least a "B" or possibly an "A," the highest rating the company school gives. If he still has no higher than the "C" rating, so far as the school courses are concerned the results are considered of an unsatisfactory nature. But the student has an opportunity at any time, through a course of study and examination, to improve his rating and this opportunity continues so long as he is in the employ of the company. Failing to get even the lower rating, however, does not mean that the student shall be discharged. The result of the school course becomes a permanent part of the student's record, influencing his position and salary to a certain extent, but not in any final sense. There have been instances in which the school record is exceedingly poor, but the service of the employe as a whole of a very high and valuable orderand this after all is the end desired.

There is one feature in favor of the corporation school which is found in no other. This is the immediate application in some practical way of the information the student acquires. Thus the lesson of today may be applied and used tomorrow and the student is immediately impressed by its value and effectiveness. On the contrary, the students of the primary and secondary schools, including the colleges, are studying at far greater distances from their activities and the application is not as immediate or direct, and the educational effort is much less efficiently made.

Reference has been made to the training classes of the company to which all new men are first assigned. It is here that the first opportunity occurs to study the personality of the new employe and it is here that he gets his first impression of the character of the service into which he has entered. It frequently happens that in advancing from the training classes to a position of greater responsibility the new employe is assigned to work for which he is temperamentally unfitted. This, however, soon becomes apparent and he is tried out in another position and, if necessary, still another until finally he reaches the work in which his best efforts may be 
absorbed. In the case of new men this is a simple proceeding, but with older employes, the problem is more difficult. The man who has been in the company's service any considerable period of time has in this experience an asset which is or should be of value to the company; he is acquainted with the service of the company and in acquiring this experience he represents a certain investment which should not be willingly lost. Usually it is some time before a new employe, in other than the operating departments, makes a direct return upon the salary he receives, thus representing a certain investment on the part of the company. Naturally it would be undesirable to lose this investment, if it can be conserved.

The result of the school courses is summed up finally in certificates, the highest being the " $\mathrm{A}$ " grade and representative of the type of man that ordinarily would fill the position of a general agent in a public utility. He must be a man acquainted with the technique of the service, with questions relating to public matters, with contracts, and have a certain degree of executive or administrative ability, through which he can direct the services of other men. The holder of this certificate need not of necessity have had practical experience in all of these directions, but in the judgment of those in charge of the educational work he must possess qualifications which would fit him for such a position.

With the four elements of our industrial life so amply provided for and the growing recognition of the importance of this fifth-this newly recognized element - there would seem to be little doubt but that the permanent and constructive activities of the country in industry and commerce will go forward by leaps and bounds, beyond our highest expectations. If there has been a weakness in our industrial life, it has been in our relative disregard of the benefits of general as well as specific education, and, broadly speaking, of the essential welfare of our industrial workers. With this element of weakness removed, and with human beings as sanely and as wisely regarded and protected as we have in the past protected our machines and our tangible properties, nothing will be needed to maintain our industrial, our financial and our human supremacy in this world. 